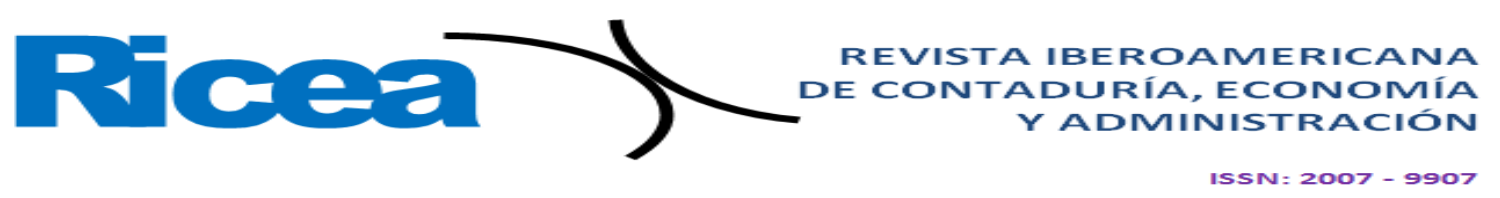

https://doi.org/10.23913/ricea.v9i17.144

Artículos Científicos

\title{
Diferencias territoriales en la economía del estado de Guerrero, México
}

\section{Territorial Differences in the Economy of the State of Guerrero, Mexico}

\section{Diferenças territoriais na economia do estado de Guerrero, México}

\author{
Ana María Hernández Salazar \\ Universidad Autónoma de Guerrero, México \\ mariana_1282@hotmail.com \\ https://orcid.org/0000-0003-2842-5804 \\ Neftalí García Castro \\ Universidad Autónoma de Guerrero, México \\ ngarciaca@conacyt.mx \\ https://orcid.org/0000-0001-5144-4224
}

\section{Resumen}

El estado de Guerrero ha sido estudiado desde la óptica de varias disciplinas de las ciencias sociales; destacan los trabajos históricos, etnográficos, antropológicos, económicos, políticos y geográficos. Pese a ello, la configuración económica-territorial de la entidad y las implicaciones sociales de esta demandan más obras que examinen los rasgos fundamentales de este estado de México. En este sentido, el análisis de la dinámica económica guerrerense desde el enfoque territorial es un aporte substancial a la elucidación de las disparidades socioeconómicas contemporáneas de dicho estado. Con tal propósito investigativo, en este artículo se utilizó la tipificación probabilística. Esta metodología se caracteriza por el contenido esencial del método de tipificación, la repetitividad territorial y la jerarquía, lo que facilita visualizar las disparidades que prevalecen en el conjunto de procesos u objetos analizados. En esta ocasión, se emplearon cuatro indicadores para evaluar el nivel de desarrollo socioeconómico que presentan los diferentes municipios guerrerenses. Con base en esto, fue posible identificar que las diferencias territoriales en la economía de Guerrero son de tipo y magnitud distinta, lo cual advierte la intervención de 


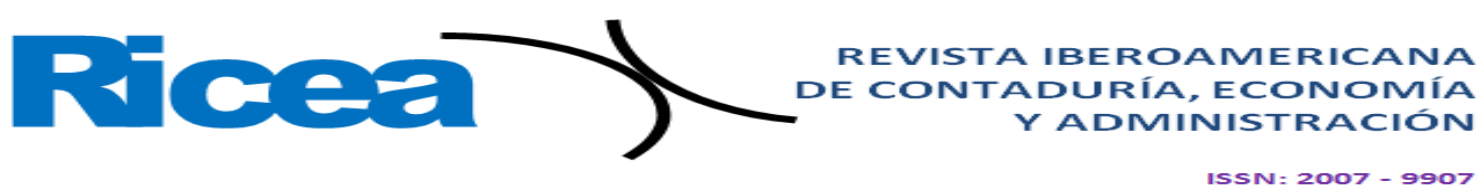

actores políticos y económicos locales, regionales, nacionales y, recientemente, multinacionales, quienes han definido las áreas donde ocurre la introducción de diversas inversiones económicas.

Palabras clave: diferencias territoriales, nivel de desarrollo municipal, tipificación probabilística.

\begin{abstract}
The state of Guerrero has been studied from the perspective of several disciplines of the social sciences, highlighting the historical, ethnographic, anthropological, economic, political and geographical works. In spite of this, the economic-territorial configuration of the entity and its implications demand more works that examine the fundamental features of this state of Mexico. In this sense, the analysis of the economic dynamics of Guerrero from the territorial approach is a substantial contribution to the elucidation of contemporary socioeconomic disparities of that state. With this investigative purpose, in this article probabilistic typification was used. This methodology is characterized by the essential content of the typing method, territorial repetitiveness and hierarchy, which facilitates visualizing the disparities that prevail in the set of processes or objects analyzed. On this occasion, four socioeconomic indicators were used to assess the level of municipal development presented by the different Guerrero municipalities. Based on this, it was possible to identify that the territorial differences in the economy of the state of Guerrero are of a different type and magnitude; they reflect the intervention of political and economic actors: local, regional, national and, recently, multinationals, who have defined the areas where the introduction of various economic investments occurs.
\end{abstract}

Keywords: territorial differences, level of municipal development, probabilistic typification.

\title{
Resumo
}

O estado de Guerrero foi estudado a partir da perspectiva de várias disciplinas das ciências sociais; Destacam-se os trabalhos históricos, etnográficos, antropológicos, econômicos, políticos e geográficos. Apesar disso, a configuração econômico-territorial da entidade e suas implicações sociais exigem mais trabalhos que examinem as características fundamentais desse estado do México. Nesse sentido, a análise da dinâmica econômica de Guerrero a partir da abordagem territorial é uma contribuição substancial para a elucidação das disparidades socioeconômicas contemporâneas desse estado. Para este objetivo de pesquisa, neste artigo foi utilizada a tipagem 


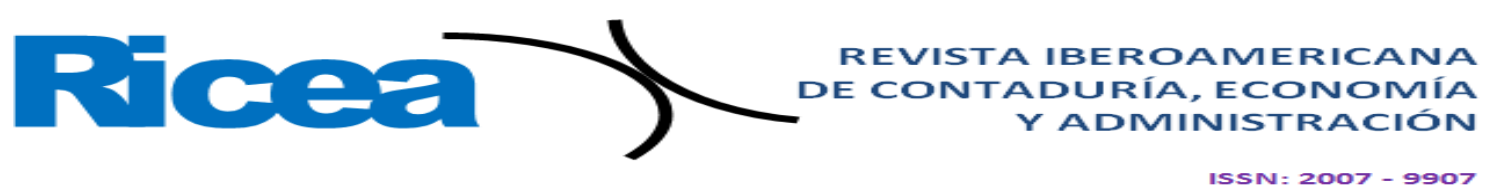

probabilística. Essa metodologia é caracterizada pelo conteúdo essencial do método de digitação, repetibilidade territorial e hierarquia, o que facilita a visualização das disparidades que prevalecem no conjunto de processos ou objetos analisados. Nesta ocasião, quatro indicadores foram utilizados para avaliar o nível de desenvolvimento socioeconômico apresentado pelos diferentes municípios de Guerrero. Com base nisso, foi possível identificar que as diferenças territoriais na economia de Guerrero são de um tipo e magnitude diferentes, o que alerta para a intervenção de atores políticos, econômicos, locais, regionais, nacionais e, recentemente, multinacionais, que definiram as áreas. onde ocorre a introdução de vários investimentos econômicos.

Palavras-chave: diferenças territoriais, nível de desenvolvimento municipal, classificação probabilística.

Fecha Recepción: Junio 2019 Fecha Aceptación: Diciembre 2019

\section{Introducción}

El objetivo de este artículo fue revelar las diferencias territoriales en la economía del estado de Guerrero. Y con tal propósito se evaluaron los niveles de desarrollo socioeconómico que existen en esta entidad de la república mexicana. En ese sentido, un referente cognoscitivo básico de esta investigación es el trabajo de Propin, Sánchez y Casado (2006), el cual explica las diferencias socioeconómicas de las entidades federativas del país. En este texto se conciben a las divergencias territoriales como noción cognitiva que permite proponer conocimientos generales útiles para el ordenamiento del territorio. Las aportaciones de las diferentes disciplinas a los trabajos del ordenamiento territorial, y en especial de la geografía con el uso de los sistemas de información geográfica, han permitido que personal técnico o personas con otra formación disciplinar logren llevar a cabo actividades relacionadas con dicho tema.

La investigación de Propin et al. (2006) mostró: 1) los niveles de desarrollo socioeconómico, los cuales se definen como la desproporción cambiante que existe entre los territorios evaluados, estimada mediante indicadores socioeconómicos seleccionados con tal fin; 2) el potencial socioeconómico, el cual se entiende, por su parte, como la expresión medible de las ventajas comparativas o factores de un territorio, y 3) la divergencia socioeconómico territorial, que engloba las cualidades disponibles de un territorio y los contrastes que existen entre el desarrollo cambiante alcanzado en este. Los hallazgos revelados para las 32 entidades de la república mexicana muestran una marcada divergencia socioeconómica. No obstante, los autores 


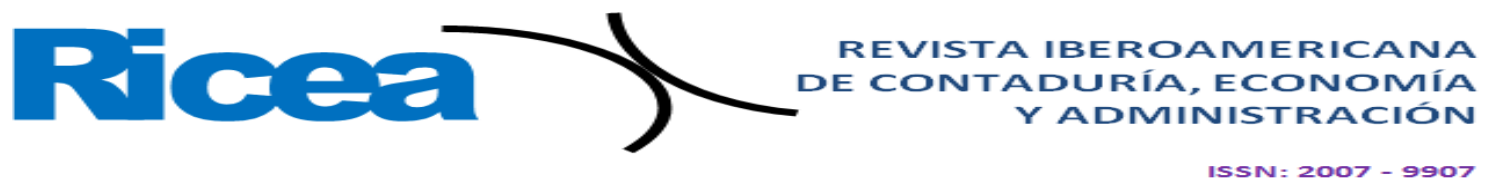

señalan que las políticas públicas, a través de sus programas de gobierno destinados al ordenamiento territorial en México, han tratado en forma igual a las 32 entidades en la asignación de recursos financieros, lo que ha generado una mayor brecha de desigualdad entre una entidad y otra, debido a sus particulares características socioeconómicas.

En el estado de Guerrero, las diferencias territoriales de la economía son de tipo y magnitud distinta; reflejan la intervención de actores políticos y económicos locales, regionales, nacionales y, recientemente, multinacionales, quienes han definido las áreas donde ocurre la introducción de diversas inversiones económicas. Para corroborar esta premisa se evaluaron los 81 municipios de la entidad desde la óptica de la tipificación probabilística y se emplearon los cuatro indicadores socioeconómicos siguientes: 1) Densidad de población (DP), 2) Grado de urbanización (GU), 3) Tasa bruta de actividad económica (TBAE) y 4) Coeficiente de dependencia económica (CDE). Cabe destacar que dicha metodología ha sido empleada en diferentes investigaciones de corte geográfico-económico debido a su utilidad para evaluar las desproporciones territoriales que suelen presentarse al interior de las entidades mexicanas. En ese orden de ideas, destacan los aportes hechos por investigadores del Departamento de Geografía Económica de la Universidad Nacional Autónoma de México [UNAM]; en particular, el trabajo de Propin y Sánchez (1998), el cual se ha consolidado como referente teórico-metodológico indispensable para aquellas obras cuyo objetivo central sea revelar las diferencias económico-territoriales.

\section{Área de estudio}

El estado de Guerrero se ubica al sur de la república mexicana. Esta entidad federativa cuenta con una extensión territorial de $63794 \mathrm{~km}^{2}$ (3.2\% de la superficie del país). La división político-administrativa guerrerense está conformada por 81 municipios, los cuales se agrupan en las regiones siguientes: Acapulco, Centro, Costa Grande, Costa Chica, Montaña, Norte y Tierra Caliente (véase tabla 1 y figura 1). De acuerdo con el Instituto Nacional de Estadística y Geografía [Inegi] (2019), Guerrero tiene 3533251 habitantes (3.0\% del total nacional). Por el número de habitantes destacan las demarcaciones siguientes: Acapulco de Juárez (810 669), Chilpancingo de los Bravo (273 106), Iguala de la Independencia (151 660), Chilapa de Álvarez (129 867), Zihuatanejo de Azueta (124 824) y Taxco de Alarcón (108 416). En Guerrero, 78 \% de la población reside en asentamientos urbanos y $22 \%$ en localidades rurales (Inegi, 2019). 


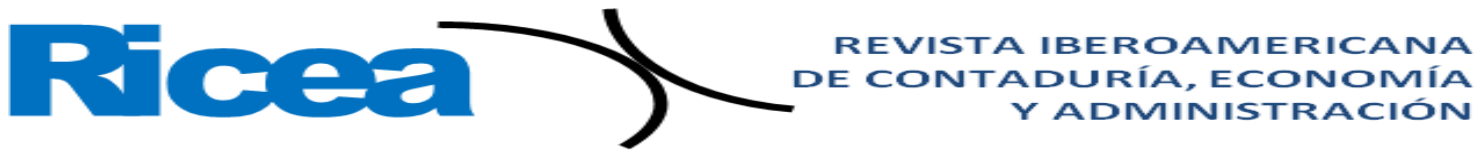

ISSN = $2007-9907$

Tabla 1. Guerrero: división político-administrativa

\begin{tabular}{|c|c|c|c|c|c|}
\hline Clave & Nombre & Clave & Nombre & Clave & Nombre \\
\hline 0 & Acapulco de Juárez & 28 & $\begin{array}{l}\text { Chilpancingo de } \\
\text { los Bravo }\end{array}$ & 56 & Técpan de Galeana \\
\hline 1 & Ahuacuotzingo & 29 & $\begin{array}{l}\text { Florencio } \\
\text { Villarreal }\end{array}$ & 57 & Teloloapan \\
\hline 2 & $\begin{array}{l}\text { Ajuchitlán del } \\
\text { Progreso }\end{array}$ & 30 & $\begin{array}{l}\text { General Canuto } \\
\text { A. Neri }\end{array}$ & 58 & $\begin{array}{l}\text { Tepecoacuilco de } \\
\text { Trujano }\end{array}$ \\
\hline 3 & $\begin{array}{l}\text { Alcozauca de } \\
\text { Guerrero }\end{array}$ & 31 & $\begin{array}{l}\text { General } \\
\text { Heliodoro } \\
\text { Castillo }\end{array}$ & 59 & Tetipac \\
\hline 4 & Alpoyeca & 32 & Huamuxtitlán & 60 & Tixtla de Guerrero \\
\hline 5 & Apaxtla & 33 & $\begin{array}{l}\text { Huitzuco de los } \\
\text { Figueroa }\end{array}$ & 61 & Tlacoachistlahuaca \\
\hline 6 & Arcelia & 34 & $\begin{array}{l}\text { Iguala de la } \\
\text { Independencia }\end{array}$ & 62 & Tlacoapa \\
\hline 7 & Atenango del Río & 35 & Igualapa & 63 & Tlalchapa \\
\hline 8 & $\begin{array}{l}\text { Atlamajalcingo del } \\
\text { Monte }\end{array}$ & 36 & Ixcateopan & 64 & $\begin{array}{l}\text { Tlalixtaquilla de } \\
\text { Maldonado }\end{array}$ \\
\hline 9 & Atlixtac & 37 & $\begin{array}{l}\text { Zihuatanejo de } \\
\text { Azueta }\end{array}$ & 65 & Tlapa de Comonfort \\
\hline 10 & Atoyac de Álvarez & 38 & $\begin{array}{l}\text { Juan R. } \\
\text { Escudero }\end{array}$ & 66 & Tlapehuala \\
\hline 11 & Ayutla de los Libres & 39 & Leonardo Bravo & 67 & $\begin{array}{l}\text { La Unión de Isidoro } \\
\text { Montes }\end{array}$ \\
\hline 12 & Azoyú & 40 & Malinaltepec & 68 & Xalpatláhuac \\
\hline 13 & Benito Juárez & 41 & $\begin{array}{l}\text { Mártir de } \\
\text { Cuilapan }\end{array}$ & 69 & Xochihuehuetlán \\
\hline 14 & $\begin{array}{l}\text { Buenavista de } \\
\text { Cuéllar }\end{array}$ & 42 & Metlatónoc & 70 & Xochistlahuaca \\
\hline 15 & Coahuayutla & 43 & Mochitlán & 71 & Zapotitlán Tablas \\
\hline
\end{tabular}




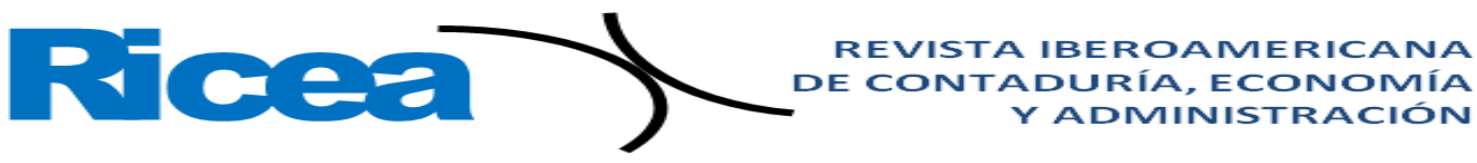

ISSN $=2007-9907$

\begin{tabular}{|c|c|c|c|c|c|}
\hline 16 & Cocula & 44 & Olinalá & 72 & Zirándaro \\
\hline 17 & Copala & 45 & Ometepec & 73 & Zitlala \\
\hline 18 & Copalillo & 46 & $\begin{array}{l}\text { Pedro Ascencio } \\
\text { Alquisiras }\end{array}$ & 74 & Eduardo Neri \\
\hline 19 & Copanatoyac & 47 & Petatlán & 75 & Acatepec \\
\hline 20 & Coyuca de Benítez & 48 & Pilcaya & 76 & Marquelia \\
\hline 21 & Coyuca de Catalán & 49 & Pungarabato & 77 & Cochoapa el Grande \\
\hline 22 & Cuajinicuilapa & 50 & Quechultenango & 78 & $\begin{array}{l}\text { José Joaquín de } \\
\text { Herrera }\end{array}$ \\
\hline 23 & Cualác & 51 & $\begin{array}{l}\text { San Luis } \\
\text { Acatlán }\end{array}$ & 79 & Juchitán \\
\hline 24 & Cuautepec & 52 & San Marcos & 80 & Iliatenco \\
\hline 25 & $\begin{array}{l}\text { Cuetzala del } \\
\text { Progreso }\end{array}$ & 53 & $\begin{array}{l}\text { San Miguel } \\
\text { Totolapan }\end{array}$ & & \\
\hline 26 & $\begin{array}{l}\text { Cutzamala de } \\
\text { Pinzón }\end{array}$ & 54 & $\begin{array}{l}\text { Taxco de } \\
\text { Alarcón }\end{array}$ & & \\
\hline 27 & Chilapa de Álvarez & 55 & Tecoanapa & & \\
\hline
\end{tabular}

Fuente: Inegi (2019) 


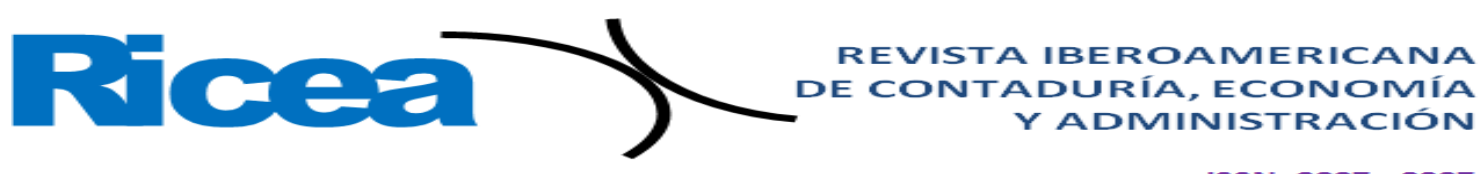

ISSN $=2007-9907$

Figura 1. Guerrero: división político-administrativa

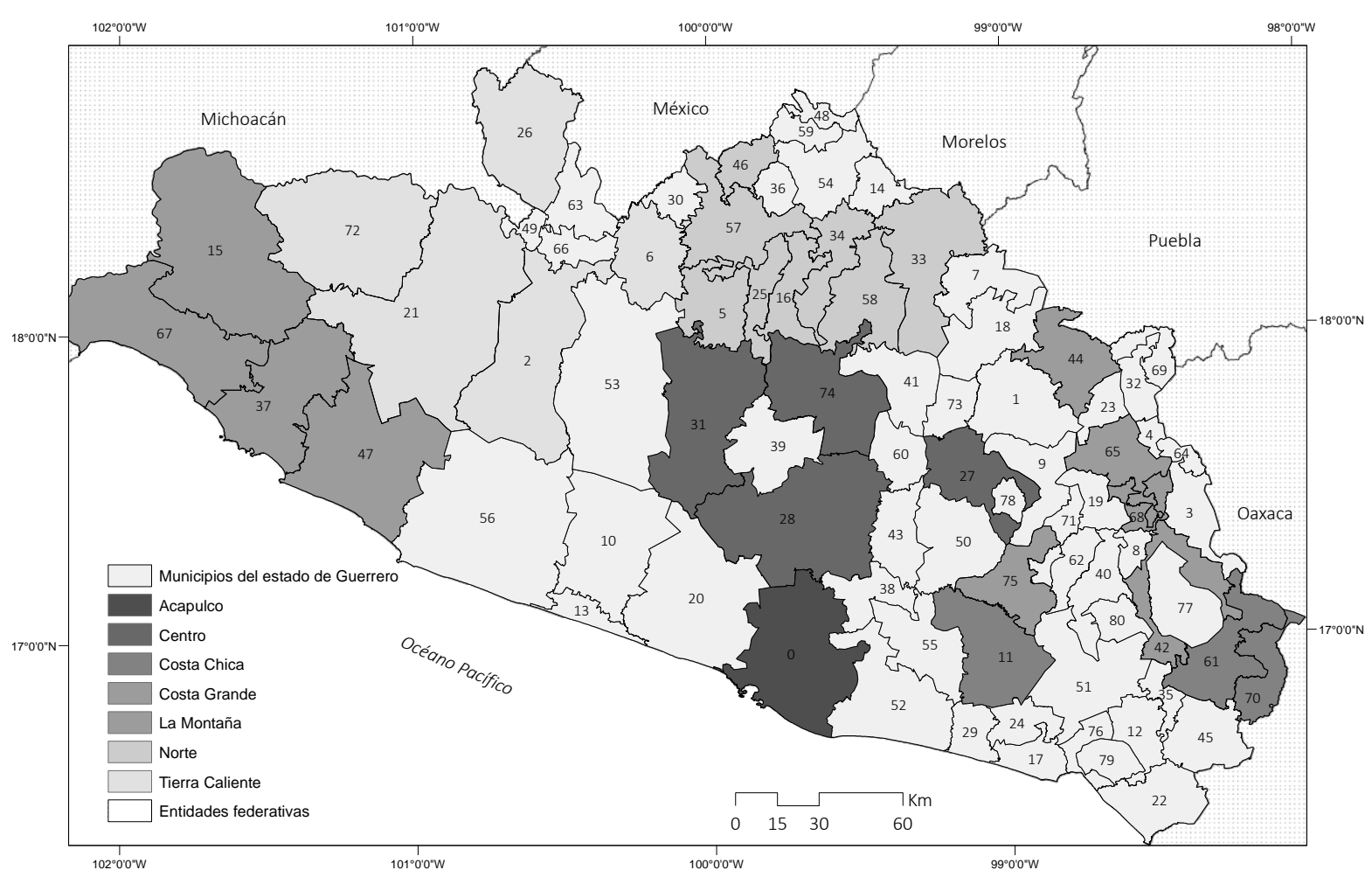

Fuente: Inegi (2019)

\section{Marco de referencia}

Para dar cuenta de las diferencias económico-territoriales del estado de Guerrero, a continuación se realiza una exposición de algunas de las principales teorías que dan pauta para explicar los hallazgos que serán revelados en los apartados subsecuentes.

a) Modelo centro-periferia. Este presenta la organización territorial, en la cual la estructura centro-periferia denota un desarrollo desigual. Mientras los centros son dotados de técnicas capitalistas, las periferias son rezagadas en términos tecnológicos y lo organizativos (Rodríguez, 1977). Los pioneros de este modelo son Myrdal (1957) y Hirschman (1973). El territorio está organizado con base en la magnitud y la distancia que existe entre el centro y la periferia; pueden presentarse múltiples centros y periferias en una misma escala territorial. 


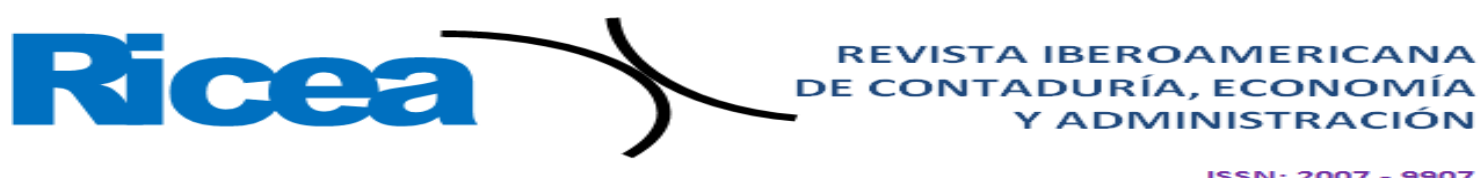

Este tipo de modelo también se define como la representación de:

La organización espacial de las actividades humanas basadas en la desigual distribución del poder en la economía y la sociedad. El centro domina (aunque puede ser dominado desde el exterior) mientras la periferia es dependiente. Estas dependencias se estructuran a través de relaciones de intercambio entre el centro y la periferia. El intercambio desigual, la concentración del poder económico, el progreso técnico y las actividades económicas en el centro y su difusión de innovaciones productivas ayudan a mantener el flujo de valores hasta la periferia (Johnston, Gregory, Haggett, Smith y Stoddart, 1981, citados en Propin, 2003, p. 53).

b) Teoría del espacio geográfico en los estados subdesarrollados. Surge de las investigaciones realizadas por Santos (1988) en torno a la periferia; centra su interés en la relación sociedad-naturaleza, y da origen al análisis del espacio geográfico. Con base en el reconocimiento de categorías existencialistas y sus posturas críticas, Santos (1988) propuso que se podía contribuir a un mundo mejor no solo basándose en la razón, sino también en la emoción. En ese sentido, la premisa es la siguiente: la necesidad de aprehender al espacio geográfico ${ }^{1}$ como expresión concreta de total competencia social a diferencia del espacio económico, abstracto y selectivo, priorizando intereses empresariales y esfuerzos de planificación. La interpretación del mundo desde la periferia ha contribuido a comprender la relación que existe entre los procesos espaciales y su articulación con los centros; la visión materialista del espacio, la vinculación con la categoría tiempo y articulación con una perspectiva de la sociedad (Zusman, 2001).

c) Teoría de la aglomeración. Esta gravita en torno a la concentración de las actividades económicas en ciudades (Manrique, 2006). Ha permitido comprender el porqué las industrias o centros de empleo se concentran en ciertos espacios, lo que sirve como atracción para llevar a cabo actividades de índole económica, política o de relaciones sociales. Al respecto, Propin (2003), citando a Larkin y Peters (1986) y Johnston (1983), expone lo siguiente:

\footnotetext{
${ }^{1}$ Santos considera al espacio como un conjunto de relaciones que se desarrollan a través de funciones y de formas que representan una historia escrita por procesos del pasado y del presente. Para este autor, una caracterización del espacio geográfico en estos términos implica entenderlo coma una forma, como un resultado objetivo de la interacción de múltiples variables en el curso de la historia, con lo cual se niega la posibilidad de entenderlo como una estructura subordinada a las otras estructuras, por ejemplo, la económica (Hiernaux y Lindon, 1993).
} 


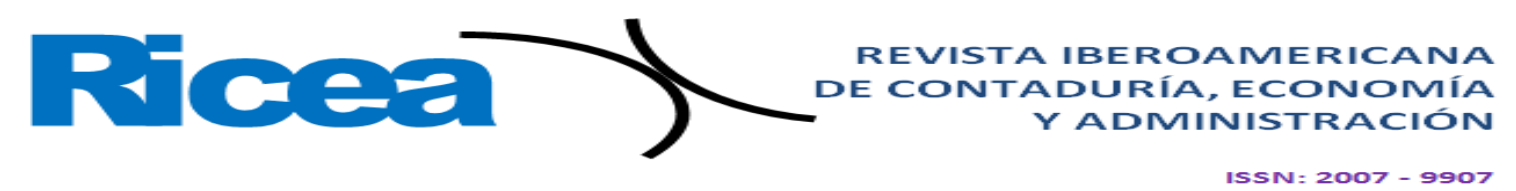

Basada en la premisa de que la expansión de la manufactura en un país es atraída en forma desproporcional hacia los centros urbanos mayores (...). La aglomeración de industria resulta cuando los costos para las firmas son reducidos como resultado de la concentración conjunta (...). Weber (1909) fue el pionero de esta perspectiva teórica, también destacan los trabajos de Haig y McCrea (1927), Lampart (1954), Perroux (1955), Boudeville (1966) y Thompson (1968) (...). Esta teoría continúa siendo un elemento importante en investigaciones del desarrollo económico y la estructura urbana (p. 51).

d) La teoría de la localización económica como marco explicativo de las disparidades territoriales en la economía puede ser abordada de dos maneras: 1) "el estudio científico de los efectos del espacio geográfico sobre la localización y distribución de actividades económicas” y 2) “el estudio científico de los patrones espaciales de las actividades económicas”, las cuales tienen como base "los trabajos de Von Thünen (1875), Weber (1909) y Lösch (1954)" (Propin, 2003, p. 48). Thünen (1875, citado en Cantón, García, León, Rico y Torcal, 1986)², en su modelo económico denominado estado aislado, presenta una sola ciudad en el centro de una llanura, en la cual los habitantes intercambiaban bienes manufacturados por productos agrícolas, siendo el automóvil el único medio de transporte, mientras que los productos agrícolas se cultivaban alrededor de la ciudad y la localización de los cultivos estaban en función del costo de transporte (costo de oportunidad); los terrenos más alejados estarían ocupados por bosques, que podían ser utilizados para roturarse en caso de una expansión de la economía.

A principios del siglo XIX, Weber buscaba un modelo teórico que explicara la localización industrial; en ese período se observó el desarrollo urbano debido a la concentración de la población alemana e inglesa cerca de los depósitos de minerales. Siguiendo a Asuad (2014), quien detalla el pensamiento de Weber, la lógica de una empresa para decidir su localización tenía dos alternativas: el mercado y las materias primas. Esto en función de la distancia física y los costos de transporte (producto terminado-material bruto), variables que deberían tomarse en cuenta para determinar sitios alternativos de localización. Años más tarde, Lösch (1955) elaboró un modelo de economía espacial. En este, el espacio cumple una variable fundamental en condiciones de competencia

\footnotetext{
${ }^{2}$ La teoría que predominaba en la explicación de la localización de las actividades económicas en el espacio se asociaba al concepto de espacio homogéneo, que partía de la hipótesis que los recursos son ubicuos con presencia en todo el espacio asociado a la igualdad de la tierra, destacando el papel de la distancia y de la localización entre los sitios de producción y consumo, lo que explicaba cómo se determinaba las áreas de producción agrícola (Thünen, 1875, citado en Cantón et al., 1986).
} 


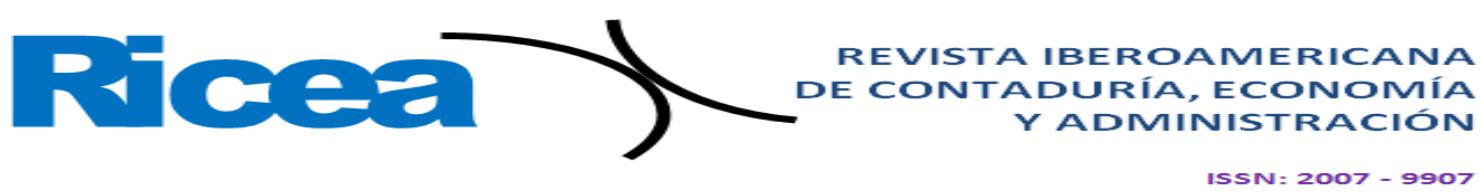

imperfecta. A través de la delimitación del área de mercado, Lösch (1955) imaginó el concepto de región económica ideal. Dicha región sería resultado de una concentración espacial según la cual todas las redes tuvieran un centro de producción común. La concentración espacial de las actividades es la conclusión a la que llega este autor, aun cuando su supuesto de partida era el reparto homogéneo de los factores productivos y de la población a lo largo de todo el espacio.

Esta revisión teórica tuvo como propósito sentar algunas bases para comprender las diferencias territoriales del estado de Guerrero. En suma, se constata la existencia de distintas teorías que permiten comprender las transformaciones socioterritoriales del espacio en cuestión; tal y como la de centro-periferia, que muestra la bipolaridad entre los centros dotados de las prácticas capitalistas y el rezago de las periferias. De esta visión emerge, a su vez, la teoría del espacio geográfico de los estados subdesarrollados, generada a partir de la periferia, donde sus procesos espaciales, la visión materialista del espacio y la categoría tiempo revelan otra manera de abordar el estudio del territorio. Asimismo, la teoría de localización económica ha permitido contar con un referente para explicar la implantación de las actividades económicas en el espacio y la concentración de las industrias especializadas en ciertas zonas urbanas; lo cual da paso a la generación de la teoría de aglomeración, que da pauta para comprender la concentración de las actividades económicas en ciertas ciudades y a diferencia de otras.

\section{Materiales y método}

A diferencia de otros métodos, en la tipificación probabilística se debe cuidar que el número de indicadores no sea mayor a cinco ni menor a tres. En esta ocasión, se tomó en cuenta el planteamiento metodológico de Propin et al. (2006). Sin embargo, al realizarse una prueba de los indicadores para los municipios que integran a Guerrero, se identificó la poca viabilidad de utilizar los mismos usados en el estudio antes mencionado. En consecuencia, se definieron cuatro indicadores que permitieron medir el nivel desarrollo socioeconómico en esta investigación (tabla 2). Cabe aclarar que el "el nivel de desarrollo socioeconómico fue definido como la desproporción relativa que yace entre los territorios estimados a partir de indicadores seleccionados" (Propin et al., 2006, p. 163). 
Tabla 2. Indicadores elegidos para medir los niveles de desarrollo socioeconómico

\begin{tabular}{|l|l|}
\hline \multicolumn{1}{|c|}{ Indicador } & \multicolumn{1}{|c|}{ Definición } \\
\hline Densidad de población (DP) & $\begin{array}{l}\text { Es el resultado de dividir la cantidad } \\
\text { de habitantes que viven en una } \\
\text { unidad territorial entre la extensión } \\
\text { de esta. }\end{array}$ \\
\hline Grado de urbanización (GU) & $\begin{array}{l}\text { Es el porcentaje que representa la } \\
\text { población de un asentamiento urbana } \\
\text { respecto a la población que vive en } \\
\text { la unidad territorial que circunscribe } \\
\text { a dicha ciudad. }\end{array}$ \\
\hline Tasa bruta de actividad económica (TBAE) & $\begin{array}{l}\text { Se calcula como el cociente } \\
\text { resultante de dividir la población } \\
\text { económicamente activa entre la } \\
\text { población total de la demarcación en } \\
\text { cuestión multiplicado por 100. }\end{array}$ \\
\hline Coeficiente de dependencia económica & $\begin{array}{l}\text { Es el resultado de dividir la suma de } \\
\text { la población menor de edad, más } \\
\text { personas de la tercera edad y } \\
\text { población desocupada, dividido entre } \\
\text { la población económicamente activa } \\
\text { ocupada, multiplicado por 100. }\end{array}$ \\
\hline
\end{tabular}

Fuente: Elaboración propia con base en Propin et al. (2006)

Con relación a los indicadores seleccionados, es importante hacer las acotaciones siguientes:

a) La distribución de la población, entre un territorio y otro, es diferente; existen lugares donde se concentra mayor población, como las ciudades, y otros con menor concentración poblacional, como ocurre en las localidades rurales. La relación entre un espacio determinado y el número de personas que lo habitan se denomina densidad de población, la cual se obtiene dividiendo el número de personas que viven en un lugar específico entre el número de kilómetros cuadrados que mide ese territorio (municipio). 


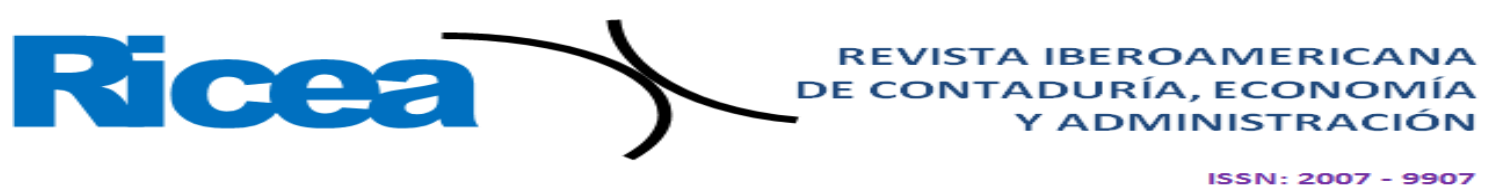

b) El porcentaje de población que reside en áreas urbanas respecto a la población total del municipio es conocido como grado de urbanización. Los cambios en la distribución de la población son un indicador de los efectos de los flujos migratorios. Los cambios en la localización de la población proporcionan, además, información sobre las necesidades de atención en materia de servicios básicos que requiere la población (Comisión Económica para América Latina y el Caribe [Cepal], 2018).

c) Se denomina tasa bruta de actividad económica porque relaciona la población económicamente activa (PEA) ocupada y el volumen total de la población, incluyendo a las personas cuya edad las incapacita para participar en la población activa. En el caso de México, solo los mayores de 12 años pueden formar parte de la PEA. Este es un criterio estrictamente censal; en realidad no se afirma que no existan trabajadores menores de 12 años (García, 1975).

d) La población municipal menor a 12 años, más la población municipal económicamente activa desocupada, más la población municipal económicamente inactiva, dividida entre la población municipal económicamente ocupada, da como resultado el coeficiente de dependencia económica; es decir, el porcentaje de población por municipio que es dependiente económicamente.

A continuación, se presentan las características elementales del método de tipificación probabilística. Este método, desarrollado por Thürmer y descrito por Propin, Ayón y de la Cruz (1985), se caracteriza por el contenido esencial del método de tipificación, la repetitividad territorial y la jerarquía, que facilita visualizar las disparidades cualitativas que prevalecen en el conjunto de procesos u objetos analizados. Por lo tanto, para las investigaciones de corte geográfico-económico se sugiere el empleo de indicadores que reflejen la interacción entre ámbito socioeconómico y el entorno físico. Dicha información se integra en una matriz que muestra su comportamiento cuantitativo en cada una de las circunscripciones del territorio abordado (ver tabla 3). Esta base de datos es la plataforma de trabajo para determinar los niveles de desarrollo socioeconómico. Y para tal fin serán cruciales las etapas descritas a continuación:

1) Clasificación cualitativa de los indicadores. Los valores de cada uno de los indicadores se ordenarán de manera ascendente para observar su variación. Esto facilitará la conformación de cinco rangos como vías de generalización cualitativa (Propin, 2003). Los calificativos que se emplearán y su codificación numérica son: muy alta (5), alta (4), media (3), baja (2) y muy baja (1) (véase tabla 4). Enseguida, se elaborará una matriz. En ella se sustituirán los valores de los cinco indicadores socioeconómicos por combinaciones de índices clasificatorios 


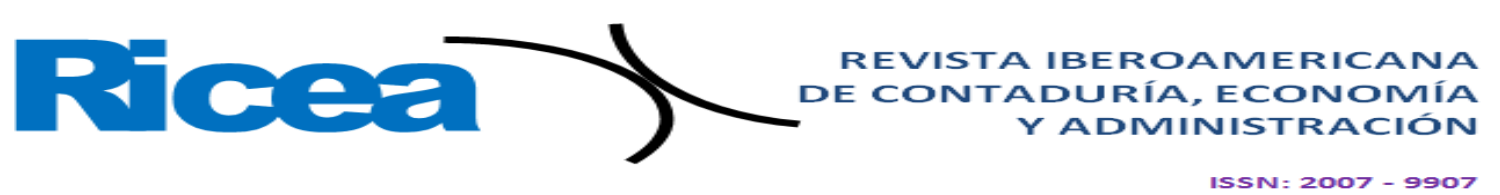

que corresponden a cada unidad espacial de referencia, según el rango asignado a su valor (tabla $5)$.

2) Conformación de las nubes tipológicas. Se elaboró una lista de las combinaciones que se presentaron, así como de la frecuencia de cada una de ellas. Eso permitió conocer todos los códigos que mostró la entidad. Los más recurrentes fueron considerados núcleos a partir de los cuales se ligaron otros que indican la existencia de circunscripciones con comportamiento socioeconómico análogo. Se usó línea continua cuando los códigos se desviaron, entre sí, en el rango de un solo indicador. Las rayas segmentadas conectaron aquellos que no cumplieron con la condición anterior. En ese caso, fue esencial ponderar la afinidad que hay entre una determinada nube y el código que se anexa (figura 2). Posteriormente, fue necesario establecer el nivel de desarrollo socioeconómico municipal que refiere cada grupo de códigos conformado. Estos se jerarquizaron con base en el comportamiento de los coeficientes de correlación exhibidos entre los cuatro indicadores socioeconómicos. Los que ostentan una reciprocidad alta se tomaron en cuenta para decidir qué lugar ocuparía una determinada nube tipológica (figura 3).

3) Revelación de la tipología. Cada nube conformada se codificó mediante una nomenclatura que tomó en cuenta el número de ocasiones en las que se presentó el rango correspondiente a cada indicador socioeconómico. Las variaciones de este se expresaron de las cuatro formas ejemplificadas a continuación (Propin, 2003).

- $\quad$ 1: Señaló la existencia de valores muy bajos en más de $90 \%$ de los códigos de una nube.

- $\quad 23$ : Indicó el predominio de un indicador con rango bajo (entre $80 \%$ y $90 \%$ del conjunto de circunscripciones que conforman al nivel). Los casos secundarios se presentaron como subíndices.

- $\quad 2_{(3)}$ : Reveló el predominio relativo de valores bajos (entre $50 \%$ y menos de $80 \%$ de los municipios muestra esa condición). Se emplearon subíndices y paréntesis para expresar otros rangos que ostentó el indicador en cuestión.

- $\quad$ 2,3: Significó que los montos bajos y medios aparecieron con la misma frecuencia. Esa situación equilibrada se registró mediante el empleo de números de igual dimensión (ver tabla $6)$. 


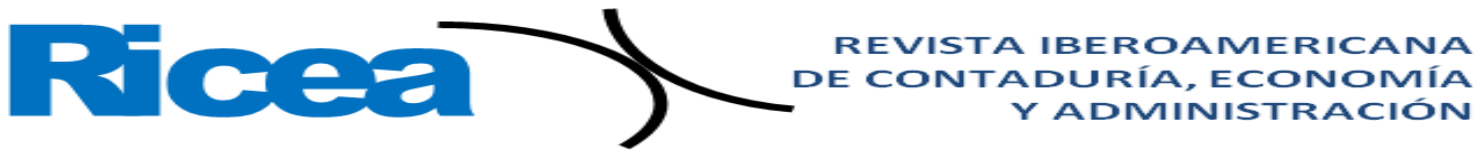

Tabla 3. Ejemplo del comportamiento cuantitativo de los indicadores seleccionados

\begin{tabular}{|c|c|c|c|c|}
\hline Municipio & $\mathrm{DP}\left(\mathrm{km}^{2}\right)$ & GU (\%) & TBAE (\%) & CDE (\%) \\
\hline Acapulco de Juárez & 470 & 84.39 & 39.07 & 146.51 \\
\hline Ahuacuotzingo & 31 & 0.00 & 18.93 & 402.32 \\
\hline Ajuchitlán del Progreso & 19 & 0.00 & 23.46 & 306.01 \\
\hline Alcozauca de Guerrero & 41 & 0.00 & 15.34 & 513.56 \\
\hline Alpoyeca & 65 & 0.00 & 26.78 & 254.80 \\
\hline Apaxtla & 18 & 0.00 & 24.14 & 293.58 \\
\hline Arcelia & 40 & 59.79 & 28.23 & 239.39 \\
\hline Atenango del Río & 15 & 0.00 & 19.41 & 391.50 \\
\hline Atlamajalcingo del Monte & 39 & 0.00 & 7.89 & 1090.74 \\
\hline Atlixtac & 47 & 0.00 & 22.30 & 322.28 \\
\hline Atoyac de Álvarez & 42 & 33.41 & 33.64 & 185.93 \\
\hline Ayutla de los Libres & 67 & 25.53 & 26.29 & 257.61 \\
\hline Azoyú & 38 & 0.00 & 30.29 & 216.61 \\
\hline Benito Juárez & 65 & 0.00 & 36.36 & 164.30 \\
\hline Buenavista de Cuéllar & 44 & 0.00 & 37.21 & 158.13 \\
\hline Coahuayutla & 5 & 0.00 & 21.21 & 348.94 \\
\hline Cocula & 30 & 0.00 & 29.35 & 226.08 \\
\hline Copala & 48 & 0.00 & 27.52 & 247.28 \\
\hline Copalillo & 20 & 0.00 & 16.88 & 459.16 \\
\hline Copanatoyac & 66 & 0.00 & 18.93 & 396.73 \\
\hline Coyuca de Benítez & 42 & 0.00 & 33.27 & 187.21 \\
\hline Coyuca de Catalán & 11 & 0.00 & 20.45 & 360.63 \\
\hline Cuajinicuilapa & 42 & 0.00 & 31.76 & 200.60 \\
\hline Cualác & 32 & 0.00 & 17.01 & 459.11 \\
\hline Cuautepec & 53 & 0.00 & 27.54 & 245.42 \\
\hline Cuetzala del Progreso & 23 & 0.00 & 20.35 & 370.38 \\
\hline Cutzamala de Pinzón & 15 & 0.00 & 21.79 & 338.72 \\
\hline Chilapa de Álvarez & 173 & 25.66 & 28.95 & 228.56 \\
\hline Chilpancingo de los Bravo & 125 & 76.68 & 39.96 & 139.84 \\
\hline
\end{tabular}




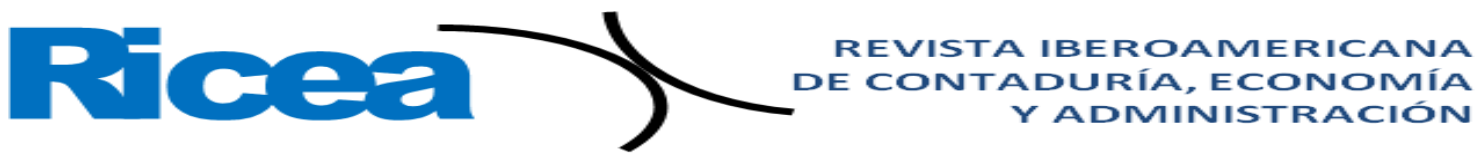

ISSN $=2007-9907$

\begin{tabular}{|c|c|c|c|c|}
\hline Florencio Villarreal & 72 & 0.00 & 31.12 & 206.72 \\
\hline General Canuto A. Neri & 23 & 0.00 & 14.93 & 538.82 \\
\hline General Heliodoro Castillo & 22 & 0.00 & 20.70 & 356.78 \\
\hline Huamuxtitlán & 53 & 0.00 & 26.88 & 256.17 \\
\hline
\end{tabular}

Fuente: Elaboración propia con base en Inegi (2019) y Consejo Nacional de Población [Conapo]

Tabla 4. Ponderación cualitativa y rangos cuantitativos de los indicadores

\begin{tabular}{|c|c|c|c|c|c|}
\hline Códigos & $\begin{array}{c}\text { Ponderación } \\
\text { cualitativa }\end{array}$ & DP $\left(\mathbf{K M}^{2}\right)$ & GU (\%) & TBAE (\%) & CDE (\%) \\
\hline I & Muy bajo & $<30$ & $<25$ & $<15$ & $<350$ \\
\hline II & Bajo & $30-60$ & $25-40$ & $15-20$ & $350-500$ \\
\hline III & Medio & $60-90$ & $40-50$ & $20-30$ & $500-600$ \\
\hline IV & Alto & $90-120$ & $50-60$ & $30-35$ & $600-750$ \\
\hline V & Muy alto & $>120$ & $>60$ & $>35$ & $>750$ \\
\hline
\end{tabular}

Fuente: Elaboración propia 


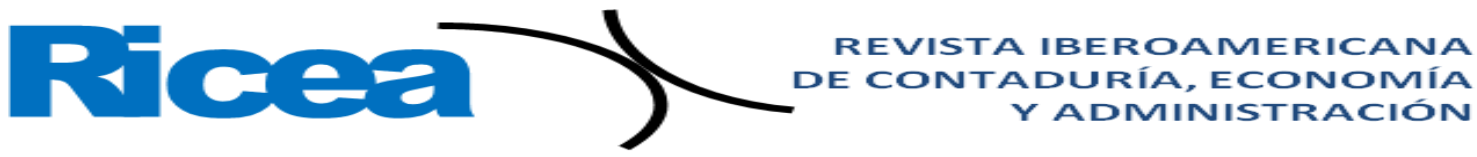

ISSN : $2007-9907$

Tabla 5. Ejemplo de la ponderación cualitativa de los indicadores seleccionados

\begin{tabular}{|c|c|c|c|c|}
\hline Municipio & DP & GU & TBAE & CDE \\
\hline Acapulco de Juárez & 5 & 5 & 5 & 1 \\
\hline Ahuacuotzingo & 2 & 1 & 2 & 2 \\
\hline Ajuchitlán del Progreso & 1 & 1 & 3 & 1 \\
\hline Alcozauca de Guerrero & 2 & 1 & 2 & 3 \\
\hline Alpoyeca & 3 & 1 & 3 & 1 \\
\hline Apaxtla & 1 & 1 & 3 & 1 \\
\hline Arcelia & 2 & 4 & 3 & 1 \\
\hline Atenango del Río & 1 & 1 & 2 & 2 \\
\hline Atlamajalcingo del Monte & 2 & 1 & 1 & 5 \\
\hline Atlixtac & 2 & 1 & 3 & 1 \\
\hline Atoyac de Álvarez & 2 & 2 & 4 & 1 \\
\hline Ayutla de los Libres & 3 & 2 & 3 & 1 \\
\hline Azoyú & 2 & 1 & 4 & 1 \\
\hline Benito Juárez & 3 & 1 & 5 & 1 \\
\hline Buenavista de Cuéllar & 2 & 1 & 5 & 1 \\
\hline Coahuayutla & 1 & 1 & 3 & 1 \\
\hline Cocula & 2 & 1 & 3 & 1 \\
\hline Copala & 2 & 1 & 3 & 1 \\
\hline Copalillo & 1 & 1 & 2 & 2 \\
\hline Copanatoyac & 3 & 1 & 2 & 2 \\
\hline Coyuca de Benítez & 2 & 1 & 4 & 1 \\
\hline Coyuca de Catalán & 1 & 1 & 3 & 2 \\
\hline Cuajinicuilapa & 2 & 1 & 4 & 1 \\
\hline Cualác & 2 & 1 & 2 & 2 \\
\hline Cuautepec & 2 & 1 & 3 & 1 \\
\hline Cuetzala del Progreso & 1 & 1 & 3 & 2 \\
\hline Cutzamala de Pinzón & 1 & 1 & 3 & 1 \\
\hline Chilapa de Álvarez & 5 & 2 & 3 & 1 \\
\hline
\end{tabular}




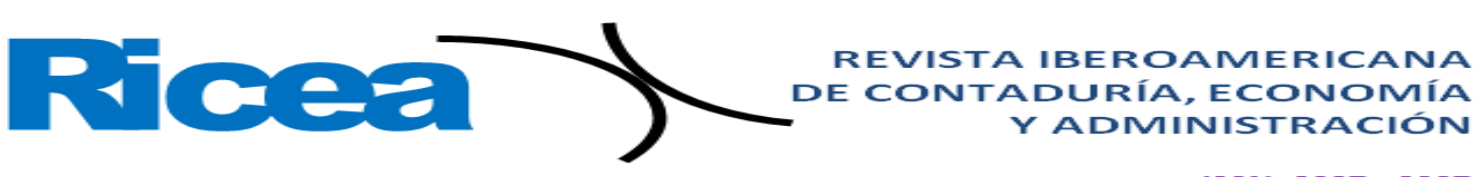

\begin{tabular}{|l|c|c|c|c|}
\hline Chilpancingo de los Bravo & 5 & 5 & 5 & 1 \\
\hline Florencio Villarreal & 3 & 1 & 4 & 1 \\
\hline General Canuto A. Neri & 1 & 1 & 1 & 3 \\
\hline General Heliodoro Castillo & 1 & 1 & 3 & 2 \\
\hline Huamuxtitlán & 2 & 1 & 3 & 1 \\
\hline
\end{tabular}

Fuente: Elaboración propia

Figura 2. Agrupación de los códigos en nubes tipológicas
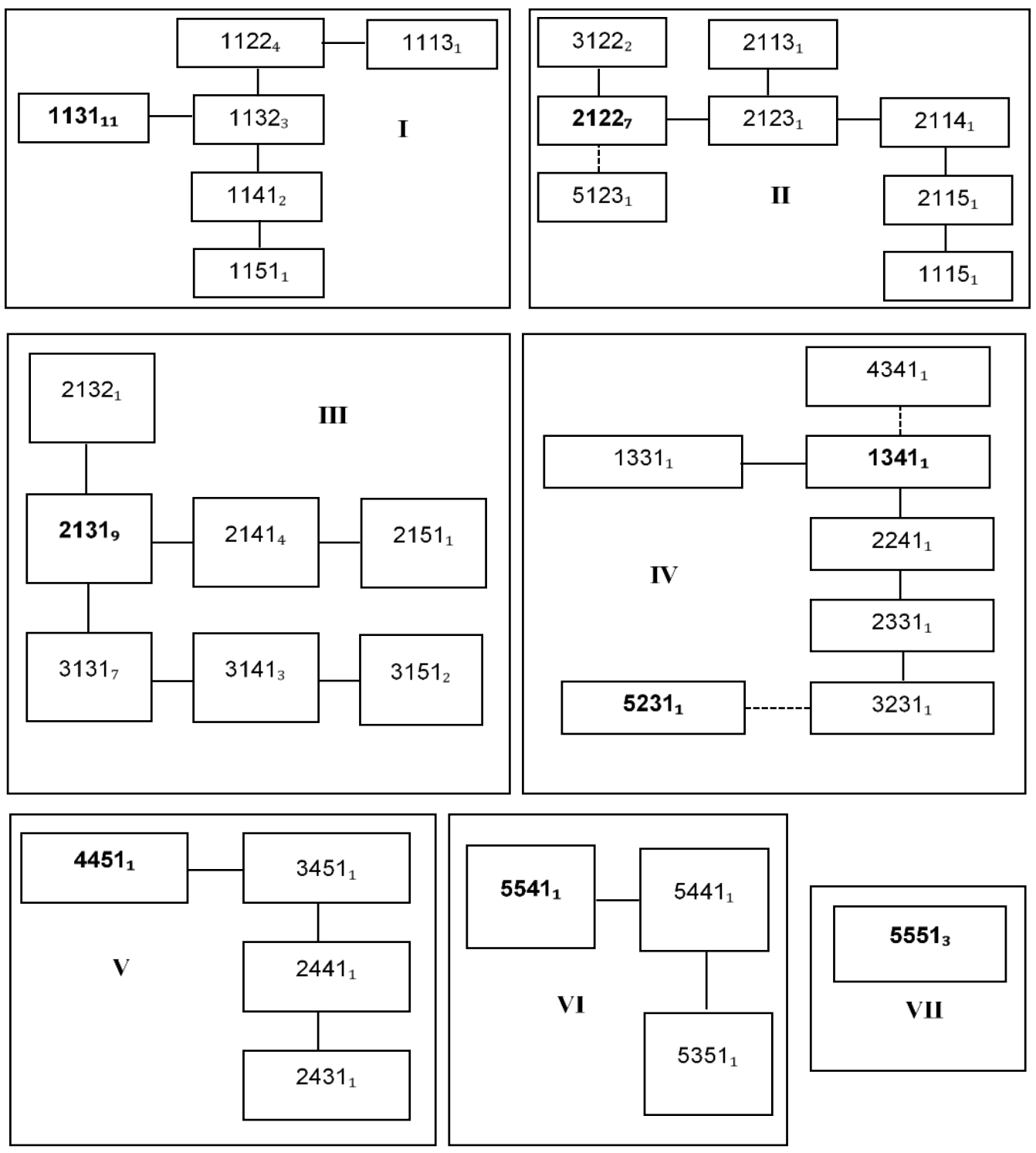

Fuente: Elaboración propia 


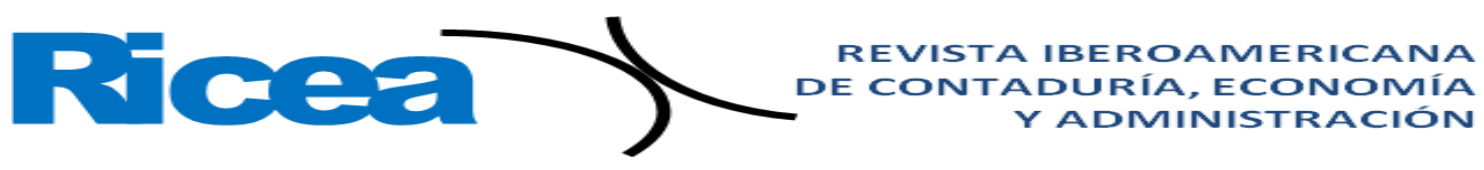

ISSN $=2007-9907$

Figura 3. Esquema de correlación de los indicadores seleccionados
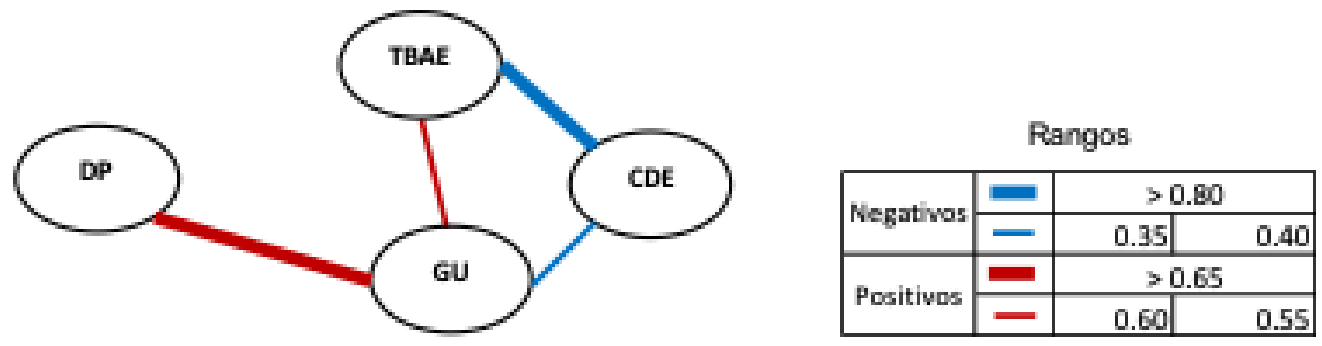

Fuente: Elaboración propia

Tabla 6. Clasificación de los municipios según ponderación cuantitativa

\begin{tabular}{|c|c|c|c|c|c|}
\hline \multirow[t]{2}{*}{ Niveles } & \multicolumn{4}{|c|}{ Indicadores } & \multirow{2}{*}{$\begin{array}{l}\text { Cantidad de } \\
\text { municipios }\end{array}$} \\
\hline & DP & GU & TBAE & CDE & \\
\hline I & 1 & 1 & $(1)(2) 3(4)(5)$ & $1_{(2)(3)}$ & 22 \\
\hline II & $1,2,3,5$ & 1 & 1,2 & $2,3,4,5$ & 15 \\
\hline III & 2,3 & 1 & $3,4,5$ & 1,2 & 27 \\
\hline IV & $1,2,3,4,5$ & 2,3 & 3,4 & 1 & 7 \\
\hline $\mathbf{V}$ & $2,3,4$ & 4 & $3,4,5$ & 1 & 4 \\
\hline VI & 5 & $3,4,5$ & 4,5 & 1 & 3 \\
\hline VII & 5 & 5 & 5 & 1 & 3 \\
\hline
\end{tabular}

Fuente: Elaboración propia

\section{Estructura municipal a partir de su nivel de desarrollo socioeconómico}

Una vez desarrollada la secuencia metodológica relacionada con la tipificación probabilística, el resultado obtenido fue la clasificación de los 81 municipios guerrerenses en siete niveles de desarrollo socioeconómico. Cada nivel está integrado por valores con una denominación cualitativa específica (muy bajo, bajo, medio, alto y muy alto) (véase figura 4). A continuación se describe cada uno de los niveles obtenidos.

- $\quad$ Nivel I. Es uno de los niveles donde se concentra el mayor número de municipios (27\% de las circunscripciones que integran a la entidad). Los valores muy bajos se presentaron en: la densidad de población (menos de 30 habitantes $/ \mathrm{km}^{2}$ ); el grado de urbanización (montos menores a $25 \%$ ), el coeficiente de dependencia económica (valores menores a $350 \%$ ); y hubo una ligera 
variación en la tasa bruta de actividad económica, ya que presentó montos muy bajos, bajos, medios y altos, salvo en Técpan de Galeana, cuya TBAE fue muy alta (mayor a $35 \%$ ). En este nivel existen seis municipios que pertenecen a la región de la Tierra Caliente, siete a la región Norte, tres de la Costa Grande, tres a la región Centro, dos a la Costa Chica y uno a La Montaña. Las unidades territoriales se localizan en seis regiones. Como se mostró en la nube tipológica, son jurisdicciones que concentran, sobre todo, montos muy bajos y bajos.

- $\quad$ Nivel II. Son 15 municipios en este nivel. Predominan valores bajos en tres de los cuatro indicadores ponderados, la densidad de población osciló entre 30 y 60 habitantes $/ \mathrm{km}^{2}$, la tasa bruta de actividad económica tuvo montos comprendidos entre $15 \%$ y $20 \%$ y el coeficiente de dependencia económica registró valores que van desde $350 \%$ hasta $500 \%$. Al igual que en el nivel I, el nivel II posee un grado de urbanización muy bajo. Además, la dependencia económica mostró montos con denominaciones cualitativas variadas, desde los valores bajos hasta los muy altos. Este nivel se presentó en los municipios de Ahuacuotzingo, Cualác, Malinaltepec, Olimalá, Quechultenango, Tlacoapa, Acatepec, Copanatoyac, Tecoanapa, José Joaquín de Herrera, Alcozauca de Guerrero, Xalpatláhuac, Metlatónoc, Atlamajalcingo del Monte y Cochoapa el Grande. Cabe destacar que 11 de los 15 municipios pertenecen a La Montaña, tres corresponden a la región Centro y uno a la Costa Chica. 


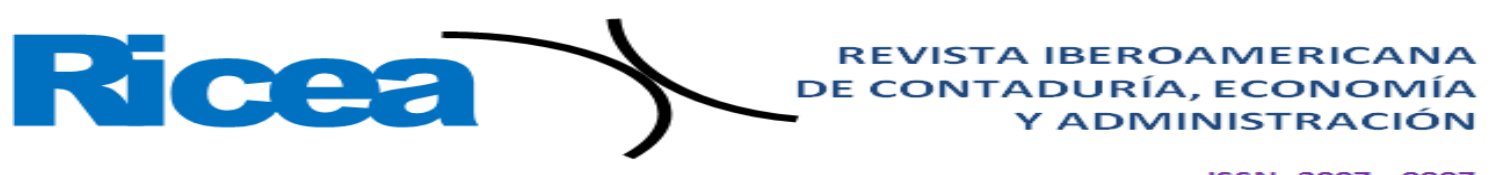

Figura 4. Guerrero: niveles de desarrollo socioeconómico

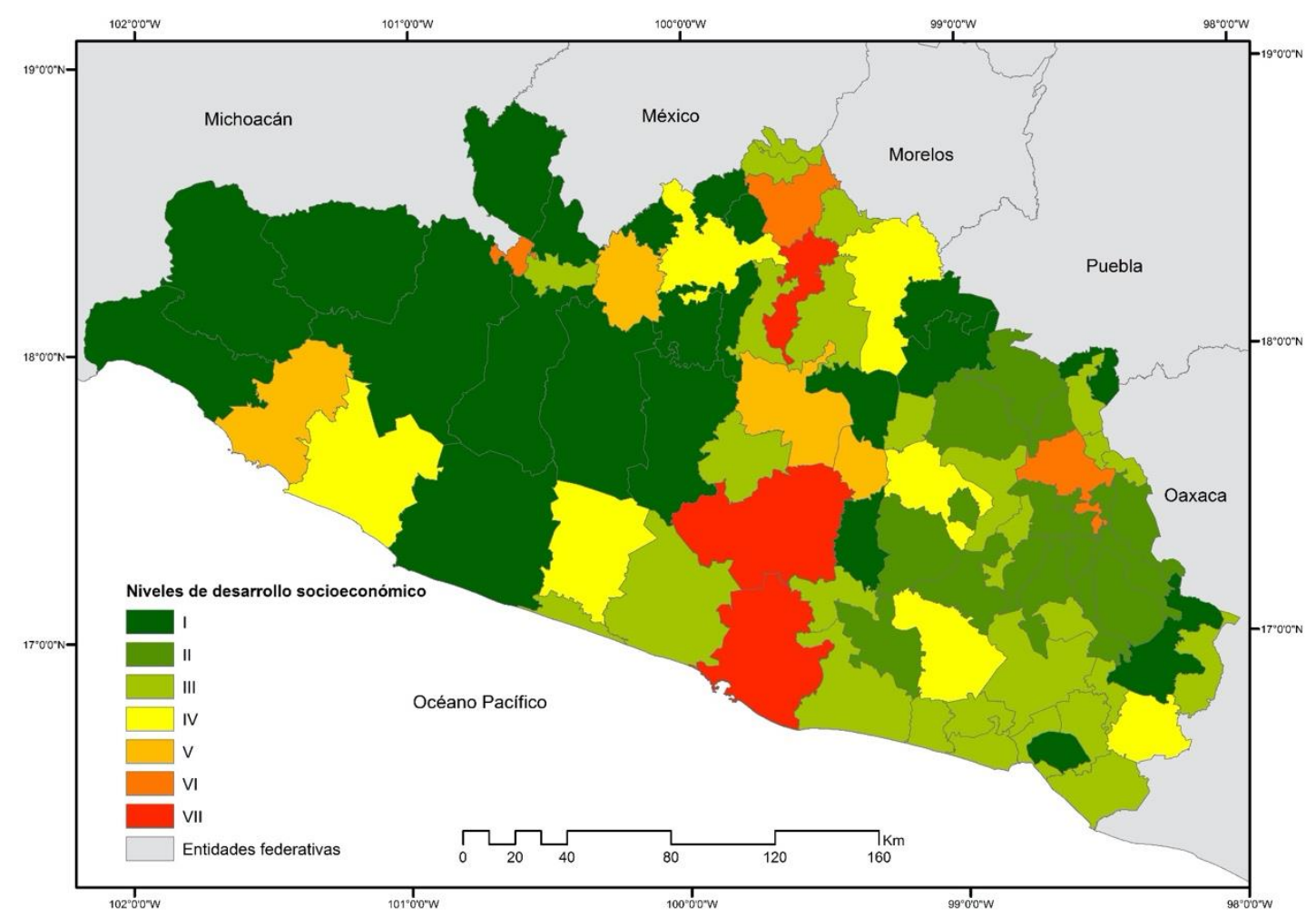

Fuente: Elaboración propia con base en Inegi (2019)

- $\quad$ Nivel III. Aquí se concentra el mayor número de municipios del estado de Guerrero, en total 27. Son demarcaciones con similitudes reflejadas en los indicadores siguientes: densidad de población (valores bajos y medios) y la tasa bruta de actividad económica (valores medios, altos y muy altos). Al igual que en el nivel I y II, en este nivel todos los municipios muestran valores muy bajos en el grado de urbanización. En el coeficiente de dependencia económica existe un comportamiento homogéneo: los municipios suelen presentar un valor muy bajo a excepción del municipio de San Luis Acatlán, que registró un valor bajo. La mayoría de las jurisdicciones pertenecen a la Costa Chica, en total nueve; seis municipios corresponden a La Montaña; cinco, a la región Norte; tres circunscripciones, a la región Centro; dos, a la Tierra Caliente; y finalmente, dos municipios a la Costa Grande. En la Costa Chica, como bien se observa en los valores obtenidos, la mayoría de los municipios guarda cierta similitud en los indicadores del NDS, a diferencia de los municipios de las otras seis regiones.

- $\quad$ Nivel IV. Es uno de los niveles más diversificados en cuanto a los montos que presentan los indicadores socioeconómicos evaluados. En este nivel se identificaron siete municipios. Y se obtuvieron valores medios en más de la mitad de las demarcaciones. Estos 


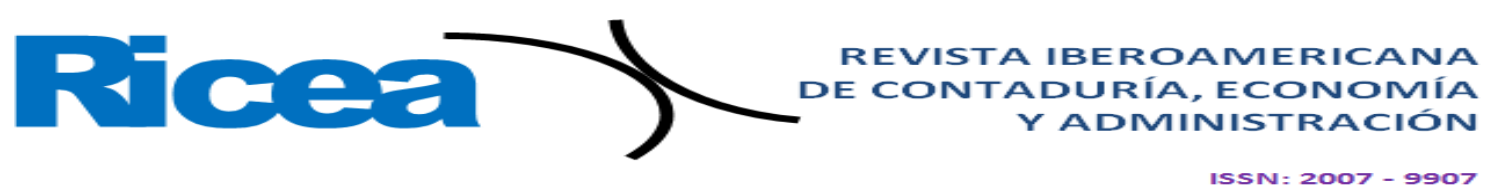

indicadores fueron: el GU y la TBAE; los montos del GU oscilaron entre $40 \%$ y $50 \%$ y la TBAE, entre $20 \%$ y $30 \%$. El único valor muy alto relacionado con la DP se presentó en el municipio de Chilapa (más de 120 habitantes $/ \mathrm{km}^{2}$ ); el resto de los municipios obtuvo valores, altos, medios, bajos y muy bajos. El indicador en el que coincidieron los siete municipios, con un valor muy bajo (menos de $350 \%$ ), fue el CDE. En cuanto a la distribución geográfica de los municipios, dos de ellos se encuentran en la Costa Grande, dos en la Costa Chica, dos en la región Norte y uno en la región Centro. A partir de este nivel, el número de municipios empieza a ser menor; además, los valores medios y altos se presentan con mayor frecuencia, lo que denota una diferencia acentuada respecto a los tres niveles antes descritos, los cuales concentran un mayor número de jurisdicciones y los valores son predominantemente menores al rango medio. Por último, los siete municipios cuentan con asentamientos cuya población es de 15000 o más habitantes, en los cuales es sobresaliente la actividad comercial y de servicios.

- $\quad$ Nivel V. El municipio de Tixtla de Guerrero y Eduardo Neri, ubicados en la región Centro; Zihuatanejo de Azueta, en la Costa Grande, y Arcelia, en la Tierra Caliente, conforman este nivel. Los cuatro presentan valores altos en el grado de urbanización (entre $50 \%$ y $60 \%$ ) y montos muy bajos relacionados con el CDE (menos de $350 \%$ ). Para el caso de la TBAE, hubo un comportamiento más heterogéneo, con valores muy altos, altos y medios. La DP presentó valores altos (entre 90 y 120 habitantes $/ \mathrm{km}^{2}$ ), medios (entre 60 y 90 habitantes $/ \mathrm{km}^{2}$ ) y bajos (entre 30 y 60 habitantes $/ \mathrm{km}^{2}$ ). Como se señaló anteriormente, el número de espacios cada vez es menor y los valores superan el rango medio; por ejemplo, el municipio de Zihuatanejo de Azueta, uno de los municipios que se ha beneficiado con las políticas económicas implementadas a mediados de los años 70 por el Gobierno federal y organismos internacionales, tiene tal comportamiento debido a la actividad turística que se desarrolla en Ixtapa-Zihuatanejo.

- $\quad$ Nivel VI. Pungarabato, Tlapa de Comonfort y Taxco de Alarcón, pertenecientes a la regiones Tierra Caliente, La Montaña y Norte, obtuvieron valores muy altos en la DP (más de 120 habitantes $/ \mathrm{km}^{2}$ ); en contraste, el CDE tuvo valores muy bajos (menos de $350 \%$ ). Por otra parte, tanto el GU como la TBAE presentaron valores muy altos, altos y medios. En este grupo llama la atención el caso de Tlapa de Comonfort como el único municipio de La Montaña con valores muy bajos en el coeficiente de dependencia económica, así como muy altos y altos en los demás indicadores, lo que denota una polarización considerable con el resto de las demarcaciones de la región. Tlapa de Comonfort, asimismo, denota que existe una brecha económico-territorial 


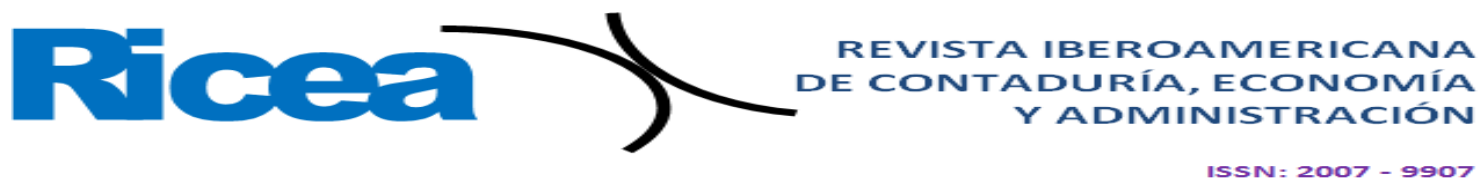

muy marcada; esto es característico de los modelos en los cuales unos territorios son favorecidos (espacios ganadores) y el resto se mantiene en el rezago.

- $\quad$ Nivel VII. Este último nivel está integrado por los municipios de Acapulco de Juárez, Chilpancingo de los Bravo e Iguala de la Independencia, pertenecientes a la región Acapulco, Centro y Norte, respectivamente. En estos municipios los valores fueron muy altos en los indicadores siguientes: DP, GU y TBAE; esto es: más de 120 habitantes $/ \mathrm{km}^{2}$ para el primer indicador; más de $60 \%$ en el segundo, y superior a $35 \%$ en el tercero. En contraste, en los tres municipios se obtuvo un valor muy bajo en el CDE (menos de $350 \%$ ). Cabe destacar que Acapulco, Chilpancingo de los Bravo e Iguala históricamente han sido espacios privilegiados por decisiones político-económicas federales y estatales, tales como la carretera Iguala-Chilpancingo en 1910, y el tramo carretero Chilpancingo-Acapulco que fue concluido en 1927, y con el cual se logró conectar al puerto de Acapulco con la región Centro y Norte, así como con el estado de Morelos y la Ciudad de México. El dinamismo económico en la región Norte por el interés que generó la extracción de minerales desde tiempos remotos mediante la bahía de Acapulco, y posteriormente las condiciones climáticas y paisajísticas, le dieron una posición privilegiada a ese sitio. En tanto, la capital del estado ha mantenido la centralización de las distintas instituciones, tanto del Gobierno federal como estatal; todo esto ha coadyuvado a la concentración de la población y crecimiento de estas ciudades.

\section{Discusión de resultados}

Si bien las 81 demarcaciones clasificadas en cada uno de los siete niveles de desarrollo socioeconómico obtenidos en la nube tipológica arrojan información valiosa, resulta difícil identificar las particularidades de cada unidad territorial a raíz del número de unidades analizadas. Por lo anterior, se retomó la definición conceptual de territorio de Damonte (2009). Esta dice que existe un primer territorio en el cual el poder es ejercido por el Estado-Nación para legitimarse como soberano del territorio nacional, y desarrolla una narrativa territorial mediante políticas públicas a través de dos principios: verticalidad y agrupamiento. En el primero, el Estado impone los espacios desde arriba a la sociedad; en el segundo, integra en un todo territorial a las diversas localidades. La concepción antes descrita se refleja en la nube tipológica obtenida. Desde los primeros asentamientos humanos establecidos en espacios que permitieron satisfacer necesidades materiales o simbólicas; y aún hoy en día, estos espacios, con una división político-administrativa, 


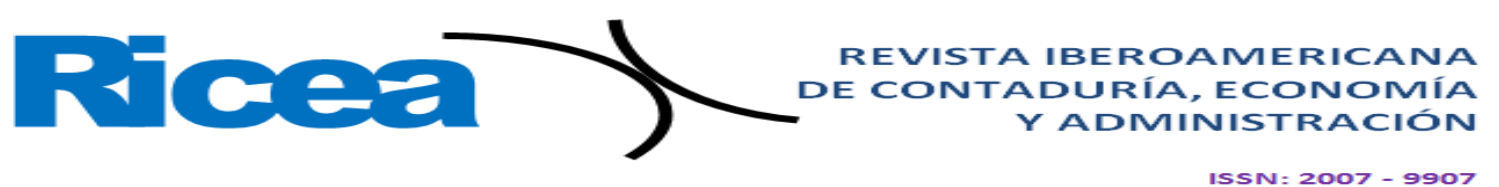

continúan siendo los centros de mayor concentración poblacional, con mayor dinamismo económico, mejores vías de comunicación, entre otras, de la entidad.

El nivel VII está conformado por territorios centrales situados únicamente en tres demarcaciones del estado de Guerrero; estos espacios socioeconómicos son núcleos que actúan de manera centrípeta, en cuanto al concepto de espacio desarrollado por Perroux (Hiernaux y Lindon, 1993). Los otros niveles que representan unidades territoriales, donde la brecha socioeconómica con estos centros es menor, son los niveles IV, V, y VI; en comparación con los niveles III, II y I, donde las diferencias socioeconómicas son muy marcadas y representaron $79 \%$ del total de territorios del estado de Guerrero. De acuerdo con el artículo "Las diferencias regionaleseconómicas del estado de Guerrero, México”, de Vázquez y Propin (2001), los lugares preferenciales donde se concentró la población, y donde se obtuvo un mayor peso económico en el estado de Guerrero, fueron: Acapulco, la porción centro y norte de la entidad, así como en la Costa Grande (cabe aclarar que la escala de análisis de esta investigación fue regional). En otra investigación realizada en la entidad, los hallazgos revelados por Propin y Sánchez (1998) fueron que el estado posee abruptos contrastes socioeconómicos entre sus territorios, al haber obtenido doce niveles de asimilación económica por la presencia de centros de primera importancia como: Acapulco, Chilpancingo, Iguala, Taxco e Ixtapa-Zihuatanejo. En general, el estado ofrece una imagen representada por centros de baja, intermedia y alta asimilación económica, con abruptos descensos, hasta territorios de bajo y extremadamente bajo nivel, excepto donde se distingue el fenómeno periférico de contacto entre localidades como Ciudad Altamirano-Tlapehuala, Chilpancingo-Chilapa, Taxco-Iguala, Tecpan-Atoyac, Ixtapa-Zihuatanejo-Petatlán y AcapulcoCoyuca de Benítez. Esta estructura territorial, a un nivel de asimilación mucho más bajo, se detecta en Ometepec-Xochistlahuaca y Tlapa-Huamuxtitlán. Han transcurrido casi dos décadas desde la última investigación mencionada y las diferencias socioeconómicas territoriales continúan manifestándose en las mismas unidades territoriales. Acapulco, Chilpancingo e Iguala han sido territorios favorecidos por inversiones públicas y privadas. Lo anterior puede originar una opinión inmediata y argumentar que estas aseveraciones son conocidas; sin embargo, la importancia de estos hallazgos radica en la identificación de unidades donde se concentran los indicadores más desfavorables y cómo las políticas económico-territoriales pueden incidir en estos territorios, y articularlos con territorios de mayor y menor dinamismo económico. 


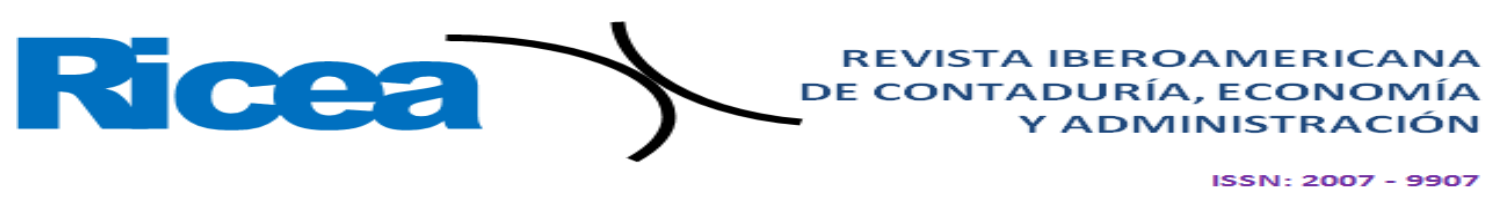

\section{A manera de conclusión}

Las diferencias territoriales en la economía del estado de Guerrero son de tipo y magnitud distinta; reflejan la intervención de actores políticos y económicos locales, regionales, nacionales y, recientemente, multinacionales, quienes han definido las áreas donde ocurre la introducción de diversas inversiones económicas. En el estado de Guerrero, desde la óptica del modelo territorial centro-periferia, son los municipios de Acapulco de Juárez, Chilpancingo de los Bravo e Iguala de la Independencia los que fungen como los principales centros con alcances regionales significativos. En ese orden de ideas, las 18 unidades territoriales que cuentan con un asentamiento humano de 15000 o más habitantes también funcionan como centros secundarios con un alcance territorial menor a las ciudades más pobladas de Guerrero (Acapulco, Iguala y Chilpancingo). Los rasgos socioeconómicos de las unidades territoriales periféricas permiten vislumbrar cómo los grupos humanos que allí se han asentado han vivido y transformado su paisaje (territorio) a lo largo de la historia, a pesar de que siempre ha estado presente una estructura que los subordina con la implementación de políticas económico-territoriales que aumentan la brecha socioeconómica entre territorios centrales y periféricos; lo anterior se refleja en el nivel I y nivel II. Esto es de suma importancia ya que una empresa busca establecerse en lugares que faciliten el acceso a las materias primas, o bien cerca del mercado, lo que contribuye a disminuir los costos de producción de sus productos y obtener mayores ganancias.

Las unidades político-administrativas sin asentamientos urbanos, con baja densidad de población y una economía tradicional se presentan en seis de las siete regiones de la entidad; sin embargo, existe una mayor presencia de estas en la región de La Montaña. Cabe destacar que en el nivel I y nivel II se concentran los municipios con los indicadores socioeconómicos más desfavorables, esto es, $46 \%$ del total de las unidades territoriales analizadas. El nivel III, con 37 $\%$ de los municipios, es el bloque donde se observa una mayor presencia de actividades económicas terciarias y primarias. La casi nula actividad industrial de la entidad se vio reflejada, en una mayor concentración de población, en aquellos lugares con más dinamismo económico y orientado a actividades terciarias: comercio, restaurantes y hoteles, transportes, comunicaciones, servicios financieros y de seguros, etc.

La brecha de desarrollo socioeconómico empieza a ser más notoria a partir del nivel IV. En este existe un menor número de unidades territoriales con población urbana y en la trama regional se advierte la aparición de espacios que suelen concentrar inversiones económicas de los sectores públicos y privados e integrarlos a un proceso de desarrollo donde el espacio económico tiene 


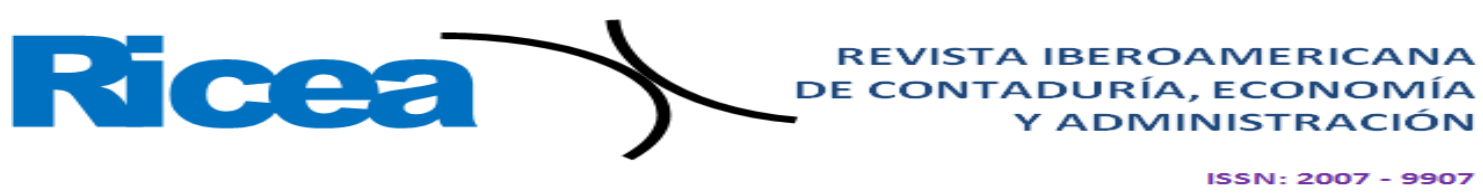

mayor peso que el espacio geográfico. Estos territorios figuran en algunos segmentos de la Costa Chica, Costa Grande y la región Centro. En términos productivos, en este nivel prevalecen las actividades terciarias. Aunado a ello, es a partir de este cuarto nivel que se hacen evidentes los postulados de la teoría de la localización económica; son aquellos espacios más poblados (urbanos) donde las empresas empiezan a localizarse (cerca del mercado) para ofertar productos finalizados, por ejemplo, las empresas de autoservicio y bancarias; así surgen centros privilegiados en la estructura regional y empieza a existir un notorio rezago en lo tecnológico y organizativo con las zonas no urbanas (periferias), y este patrón se reproduce a menor escala (cabeceras municipales y localidades). Por lo antes descrito, urge aprehender el espacio geográfico como expresión concreta de total competencia social y no únicamente como espacio económico.

A partir del nivel V, con $5 \%$ de los territorios analizados, los indicadores socioeconómicos empiezan a reflejar mejores condiciones socioeconómicas; son espacios con alguna forma de especialización en el sector terciario. La relevancia económica de estos territorios comienza a hacer más notoria la magnitud y distancia que guardan con los niveles I, II, III y IV; lo que detona la polarización entre los centros y periferias. En el nivel VI tienen importancia las actividades terciarias y secundarias. Estos son los territorios con mayor densidad de población y población urbana. Los municipios cuentan con indicadores favorables en su desarrollo socioeconómico. El nivel VII representó $4 \%$ del total de demarcaciones territoriales que conforman al territorio guerrerense. Las actividades terciarias y secundarias fueron las predominantes. Además, en este nivel se obtuvieron los indicadores socioeconómicos más favorables respecto al resto de unidades analizadas. En este nivel se concentró 35 \% de la población total de la entidad registrada en 2015. Los factores que han tenido peso para que estos municipios sean considerados como urbanos están asociados a ciertos espacios donde se encuentran los centros de empleos que han servido como sitios de atracción para la población del resto de las jurisdicciones. Por último, a lo largo de la historia y hasta en la actualidad, han sido favorecidos por inversiones tanto públicas como privadas destinadas para la construcción de vías de comunicación como carreteras, proyectos de planeación urbana, por citar un ejemplo en la bahía de Acapulco. 


\section{Referencias}

Asuad, N. (2014). Teoría de la localización industrial y de áreas de mercado. México: Universidad $\begin{array}{llll}\text { Autónoma } & \text { de } & \text { México. } & \text { Recuperado }\end{array}$ http://www.economia.unam.mx/cedrus/descargas/TeorialocalizacionIndustrial.pdf.

Cantón, R., García, I., León, F., Rico, J. y D. Torcal (1986). La vida y la obra de Johann Heinrich Von Thünen (1783-1850). Cuadernos de Ciencias Económicas y Empresariales, 17(1), 203-238.

Comisión Económica para América Latina y el Caribe [Cepal]. (2018). Grado de urbanización. Recuperado

https://celade.cepal.org/redatam/pryesp/cairo/WebHelp/Metalatina/grado_de_urbanizacio n.htm.

Consejo Nacional de Población [Conapo]. (2015). Índice y grado de marginación y lugar que ocupa en el contexto nacional y estatal por municipio, 2015. Ciudad de México, México: Consejo Nacional de Población.

Damonte, G. (2009). Territorialidades y territorios en comunidades aymaras en Perú y Bolivia. Argumentos, 3(1).

García, B. (1975). La participación de la población en la actividad económica. Demografía y economía, 9(1), 1-31.

Hiernaux, N. y A. Lindon, (1993). El concepto de espacio y análisis regional. Revista de historia y ciencias sociales, 25(1), 89-110.

Hirschman, A. (1973). Desarrollo y América Latina. Obstinación por la esperanza. Ciudad de México, México: Fondo de Cultura Económica.

Instituto Nacional de Estadística y Geografía [Inegi]. (2019). Sistema Estatal y Municipal de Base de Datos [Simbad]. México: Instituto Nacional de Estadística y Geografía. Recuperado de http://sc.inegi.org.mx/cobdem/contenido.jsp?rf=false\&solicitud=\#.

Lösch, A. (1955). The Economics of Location. American Journal of Agricultural Economics, 37(2), 376-377.

Manrique, O. (2006). Fuentes de las economías de aglomeración: una revisión bibliográfica. Cuadernos de economía, 24(45), 53-73.

Myrdal, G. (1957). Economic Theory and Underdeveloped Regions. London, England: University Paperbacks, Methuen. 
Propin, E. (2003). Teorías y Métodos en Geografía Económica. Ciudad de México, México: Instituto de Geografía de la Universidad Nacional Autónoma de México.

Propin, E., Ayón, T. y de la Cruz, P. (1985). Consideraciones sobre la determinación de orientaciones de uso de la tierra en el municipio de Pinar del Río. (reporte de investigación). Instituto de Geografía de la Academia de Ciencias de Cuba, La Habana.

Propin, E. y Sánchez, Á. (1998). Niveles de asimilación económica del estado de Guerrero. Investigaciones geográficas, 37(1), 59-70.

Propin, E., Sánchez, Á. y Casado, J. M. (2006). Las divergencias socioeconómicas territoriales como alternativa metodológica del ordenamiento territorial en México. Geographicalia, 49(1), 157-175.

Rodríguez, O. (1977). Sobre la concepción del sistema Centro-Periferia. Revista de la Comisión Económica para América Latina y el Caribe, 3(1), 203-247.

Santos, M. (1988). Metamorfose do espaço habitado. São Paulo, Brasil: Hucitec.

Vázquez, V. y Propin, E. (2001). Las diferencias regional-económicas del estado de Guerrero, México. Investigaciones geográficas, (46).

Zusman, P. (2001). Milton Santos. Su legado teórico y existencial (1926-2001). Documents d'Anàlisi Geogràfica, 40(1), 205-219. 


\begin{tabular}{|c|c|}
\hline Rol de Contribución & Autor (es) \\
\hline Conceptualización & Ana María Hernández Salazar \\
\hline Metodología & Ana María Hernández Salazar \\
\hline Software & Neftalí García Castro \\
\hline Validación & Neftalí García Castro \\
\hline Análisis Formal & Neftalí García Castro \\
\hline Investigación & Ana María Hernández Salazar \\
\hline Recursos & Ana María Hernández Salazar \\
\hline Curación de datos & Ana María Hernández Salazar \\
\hline $\begin{array}{l}\text { Escritura - Preparación del } \\
\text { borrador original }\end{array}$ & Ana María Hernández Salazar \\
\hline $\begin{array}{l}\text { Escritura - Revisión y } \\
\text { edición }\end{array}$ & Neftalí García Castro \\
\hline Visualización & Neftalí García Castro \\
\hline Supervisión & Neftalí García Castro \\
\hline $\begin{array}{l}\text { Administración de } \\
\text { Proyectos }\end{array}$ & Ana María Hernández Salazar \\
\hline Adquisición de fondos & Ana María Hernández Salazar \\
\hline
\end{tabular}

